\title{
Expression of Pulmonary Metallothionein Genes in Late Gestational Lambs
}

\author{
BRUCE R. PITT, MARGARET A. BROOKENS, A. REGINA STEVE, ARTHUR B. ATLAS, \\ PAUL DAVIES, SHIUM-MING KUO, AND JOHN S. LAZO
}

Department of Pharmacologv. University of Pittsburgh School of Medicine, Pittshurgh, Pennsylvania 15261

\begin{abstract}
Metallothioneins (MT) are low molecular weight proteins that are important in providing protection against heavy metals such as cadmium. Other precise physiologic roles for this family of proteins are less clear, but fetal hepatic cell proliferation and differentiation may be regulated through changes in MT levels and attendant MT-mediated regulation of zinc levels. The role of $M T$ in other developing tissue, most notably lung, is far less clear. Although expression of MT has been reported to be extremely low in early postnatal and mature lung, we hypothesized that MT has a more ubiquitous role in organ development and that pulmonary MT levels may be elevated during periods of rapid lung growth. Thus, we studied expression of MT in late-gestation fetal lambs. Sheep are particularly useful because alveolarization of lung parenchyma occurs before birth (by d 120 of a normal 147-d gestation). Immunoreactive MT was localized to bronchial epithelium of fetal, newborn, and mature sheep. The intensity of staining was greatest in the 130-d gestational age (saccular) lung, where positive reaction product was noted in the cytoplasm and nucleus of alveolar epithelial and interstitial cells. We next evaluated MT expression in developing lung tissue using Northern blot analysis and ${ }^{32} \mathrm{P}$-cDNA probes against the 3 '-untranslated regions of mRNA encoding each of four known functional sheep MT (sMT) isoforms. Expression of sMT-II, sMT-Ia, and sMT-Ib was restricted to the saccular stage (120-132 d gestational age), and sMT-Ic mRNA was not detected in pulmonary samples from any stage of development. In contrast, all mRNA isoforms were expressed in fetal and newborn liver and at levels considerably greater than lung. These data show that pulmonary MT gene expression is apparent in the saccular stage of lung development when considerable remodeling of lung parenchyma occurs. In addition, an organ- and age-specific expression of MT mRNA isoforms in developing sheep lung and liver was noted for the first time, suggesting that MT isoforms may play specific roles in organ development. (Pediatr Res 32: 424-430, 1992)
\end{abstract}

\section{Abbreviations}

MT, metallothionein

sMT, sheep metallothionein

g.a., gestational age

Received January 22, 1992; accepted June 5, 1992.

Correspondence and reprint requests: Dr. Bruce R. Pitt, Department of Pharmacology, University of Pittsburgh School of Medicine. Pittsburgh. PA 15261.

Supported in part by grants from the National Institutes of Health (HL-32154 and $\mathrm{HL}-41811)$ and American Cancer Society $(\mathrm{CH}-486)$. This work was performed during the tenure of B. R. Pitt as an Established Investigator of the American Heart Association and J. S. Lazo as USPHS Research Career Development Awardee.
MT are small (approximately $7 \mathrm{kD}$ ), cysteine-rich (approximately $30 \mathrm{~mol} \%$ ) metal-binding proteins $(1,2)$. All vertebrates have two isoforms of MT, MT-I and MT-II, based on elution profiles from diethylaminoethyl columns. In humans (3) and sheep (4), several subisoforms have been identified by chromatography and genes encoding these isoforms have been sequenced. Although precise physiologic roles for members of this multigene family remain unknown, it has been suggested that one major function of $\mathrm{MT}$ is to affect intracellular metal ion homeostasis $(1,2,5,6)$. MT are the major zinc-binding proteins of cells, and thus indirect regulation of numerous biologic processes that involve zinc metalloenzymes (i.e. differentiation, proliferation, energy metabolism, transcription, and antioxidant systems) is highly likely. These possibilities underscore investigations of the regulation of MT expression in developing liver $(7-10)$ in which MT has been hypothesized to protect liver against toxic levels of zinc (11) or provide zinc during critical periods of hepatocyte proliferation and differentiation (12).

In contrast to expression in liver, little is known regarding expression of MT in developing lung (13). Whole lung MT levels are detectable in 1-d-old rats and then decrease rapidly (within days) to very low adult levels $(14,15)$. Adult rat MT levels are not detectable with an immunohistochemical technique (16), and localization of MT mRNA with in situ hybridization techniques shows limited amounts of transcripts restricted to chrondrocytes and interstitial cells (perhaps fibroblasts) in newborn rabbit lung (17).

As a first approach in establishing a role for MT in developing lung, we studied the immunocytochemical localization of MT expression in lungs of lambs representative of the glandular, canalicular, and saccular periods of fetal development. Because all existing polyclonal antibodies including the one used in our study (18) fail to discriminate among MT isoforms, we then studied expression of mRNA of four SMT isoforms in developing lung using cDNA probes with minimal cross-hybridization (19). We report that bronchial epithelium of animals of all ages expressed immunoreactive MT, with additional significant MT associated within the cytoplasm and nucleus of alveolar epithelial and interstitial cells of the saccular (130-d g.a.) lamb. Steadystate mRNA of sMT isoforms Ib and II (and to a lesser extent, sMT-la) were readily detectable in lungs of fetal lambs (126 to $132 \mathrm{~d}$ g.a.), whereas expression of all four isoforms of MT mRNA in liver was measurable in much greater quantities than in lung.

\section{MATERIALS AND METHODS}

Animals. Dated pregnant ewes were killed by i.v. sodium pentobarbital, and the dead fetus (79-140 d g.a.; term approximately $147 \mathrm{~d}$ ) was quickly exteriorized. The age of the fetus was confirmed by long bone length. A 4-d-old lamb and two pregnant ewes were also killed by i.v. pentobarbital.

Immunolocalization of pulmonary MT. Representative tissue from the lungs of fetal $(85,112$, and $130 \mathrm{~d}$ g.a.), newborn $(4 \mathrm{~d}$ old), and adult sheep was taken for immunolocalization of MT. 
Small blocks of tissue were fixed by immersion in $4 \%$ (para)formaldehyde, cryoprotected in $30 \%$ sucrose in phosphate buffer, and snap frozen in liquid nitrogen. Frozen sections were cut on a Reichert-Jung (Cambridge Instruments, Boston, MA) $2800 \mathrm{E}$ cryostat and mounted on poly-L-lysine coated glass slides. Sections were blocked in $2 \%$ goat serum in PBS for $30 \mathrm{~min}$ before applying purified polyclonal rabbit anti-MT at a dilution of 1:20 in PBS and incubating overnight at $4^{\circ} \mathrm{C}$. Control sections were incubated with similarly diluted antibody that had been preincubated with 1:1 mixture of rabbit liver MT-I and -II (Sigma Chemical Co., St. Louis, MO), each at a concentration of $1 \mathrm{mg} /$ $\mathrm{mL}$. Primary antibody was generated by immunizing rabbit with rabbit liver MT. Immunoreactivity was confirmed by ELISA. Antisera was then purified by MT-conjugated sepharose 4B column. Sections were rinsed in PBS and incubated in biotinylated goat anti-rabbit IgG at a dilution of 1:200 in PBS for $1 \mathrm{~h}$ at room temperature. After several rinses, the sections were incubated in extravidin-peroxidase at a dilution of 1:20 for $1 \mathrm{~h}$ at room temperature. Substrate solution was then added, which consisted of a freshly prepared 1:1 mixture of an aqueous solution of urea-peroxide and $1 \mathrm{mg} / \mathrm{mL}$ solution of $3,3^{\prime}$-diaminobenzidine tetrahydrochloride in $0.1 \mathrm{M}$ acetate buffer, $\mathrm{pH}$ 6.0. Color development was terminated by washing with PBS. The sections were counterstained in Mayer's hematoxylin, mounted in Permount (Biomedica Corp., Foster City, CA) and viewed in a Nikon Mikrophot photomicroscope.

$R N A$ preparation. RNA was isolated by the single-step method of Chomczynski and Sacchi (20) from lung and liver parenchyma of fetal ( 79 to $140 \mathrm{~d}$ g.a.), newborn ( $4 \mathrm{~d}$ old), and two maternal sheep. Briefly, tissue was homogenized at room temperature in a denaturing solution containing $4 \mathrm{M}$ guanidinium isothiocyanate and RNA was extracted in a phenol/chloroform mixture. After precipitation of RNA with isopropanol, the pellet was washed with $75 \%$ ethanol and solubilized in $0.5 \%$ SDS. Absorption of RNA was determined at 260 and $280 \mathrm{~nm}$.

Northern blot hybridization and analyses. Analysis of SMT isoforms and $\beta$-actin mRNA levels was performed according to a modification of the method of Church and Gilbert (21). A small aliquot of total RNA $(10 \mu \mathrm{g})$ was precipitated in ethanol and dried via vacuum centrifugation (SpeedVac Concentrator, Savant Instruments Inc., Farmingdale, NY). The sample was resuspended in loading buffer (formamide, 3-(N-morpholino)propane sulfonic acid buffer, formaldehyde, diethyl pyrocarbonate water, ethidium bromide, $50 \%$ glycerol, EDTA, and bromophenol blue) and heat $\left(65^{\circ} \mathrm{C}\right), 10 \mathrm{~min}$ denatured. Samples were then subjected to $1.0 \%$ agarose gel electrophoresis. After assessing the integrity of the fractionated RNA by UV illumination of ethidium bromide staining, the RNA was transferred from the gel to GeneScreen (Dupont, Cambridge, MA) via capillary action and cross-linked to the filters by UV radiation. The previously described (19) cDNA probes for SMT-Ia, sMTIb, sMT-Ic, and sMT-II were for the $3^{\prime}$ untranslated region of mRNA and were generously provided by J. Mercer (Victoria, Australia). Hybridization was performed in $50 \%$ formamide, $0.25 \mathrm{M} \mathrm{NaHPO}_{4}$ (pH 7.2), $0.25 \mathrm{M} \mathrm{NaCl}, 1 \mathrm{mM}$ EDTA, $100 \mu \mathrm{g} /$ $\mathrm{mL}$ denatured salmon sperm DNA, and $7 \%$ SDS at $42^{\circ} \mathrm{C}$ overnight with approximately $1 \times 10^{6} \mathrm{cpm}$ probe $/ \mathrm{mL}$ hybridization buffer. GeneScreen filters were washed six times: two times in $\mathrm{NaCl}$ /sodium citrate and $0.1 \% \mathrm{SDS}$, twice in $25 \mathrm{mM}$ sodium phosphate, $1 \mathrm{mM}$ EDTA, and $1 \%$ SDS, and twice in $25 \mathrm{mM}$ sodium phosphate, $1 \mathrm{mM}$ EDTA, and $1 \% \mathrm{SDS}$, all at $50^{\circ} \mathrm{C}$. cDNA probes encoding sMT or $\beta$-actin [pHF beta A-1 (22)] were radiolabeled with $\alpha{ }^{32} \mathrm{P}$-cytidine 5'-triphosphate by random primer extension (23) with Klenow fragment (Boehringer Mannheim) to a sp act greater than $10^{9} \mathrm{dpm} / \mu \mathrm{g}$.

Hybridization signal. The hybridization signal for $10 \mu \mathrm{g}$ total RNA was determined by scanning densitometry (LKB Ultrascan XL, Piscataway, NJ) of autoradiographic exposures (Kodak XOmat AR film plus Dupont Cronex intensifying screen, $-70^{\circ} \mathrm{C}$ ) of the hybridized filters. The signal area associated with previ- ously reported sizes of transcripts for MT was determined by integration with LKB 2400 GelScan XL software. The ratio of mRNA signal to the $\beta$-actin mRNA signal was calculated. Occasionally, blots would be allowed to develop for longer periods to allow detectable levels of less abundant signals to be apparent. In these cases, comparisons within the same blot (developed on two different occasions) were normalized to lanes of RNA whose signal was within a linear range. The filters were stripped after each hybridization by treating them with $5 \mathrm{mM}$ EDTA and were rehybridized to either sMT or $\beta$-actin probes. The above procedure was done on several occasions with similar results regardless of the sequence in which the filters were stripped.

Cross-hybridization of MT cDNA probes via Southern analysis. To assess the degree of cross-hybridization of the various cDNA probes under the above conditions, we performed Southern blot analysis of restriction reactions of the various MT isoform plasmids. Briefly, plasmids BP-1/64, SSE-1/64, SEP-2/64, and Sh $33 / 65$ (19) were digested with HindIII and EcoRI to release respective inserts. The products were fractionated on a $1.8 \%$ agarose in Tris-borate EDTA gel and transferred to GeneScreen according to the manufacturer's instructions. Hybridization was performed in $30 \%$ formamide, $10 \%$ dextran sulfate, $1 \times$ Denhardt's at $47^{\circ} \mathrm{C}$ overnight with $1 \times 10^{6} \mathrm{cpm} / \mathrm{mL}$ of ${ }^{32} \mathrm{P}-\mathrm{cDNA}$ sMT for $15 \mathrm{~min}$ and then the GeneScreen filter was washed three times in 0.2 sodium chloride sodium citrate, $0.1 \%$ SDS at $47^{\circ} \mathrm{C}$ for $1 \mathrm{~h}$. Autoradiographs were developed for brief periods (12 $\mathrm{min}$ ) to estimate relative cross-hybridization signals.

\section{RESULTS}

The morphology of the lungs was representative of all phases of pulmonary development from pseudoglandular to saccular/ alveolar (Fig. 1). At $85 \mathrm{~d}$ g.a. (Fig. $1 A$ ), the lung was typically pseudoglandular with an unorganized mesenchymal stroma transected by large bronchioles and many small putative airways lined by cuboidal, nonciliated epithelial cells. The canalicular stage was represented at 112 d g.a. (Fig. 1B). Saccular/alveolar morphology was already evident at $130 \mathrm{~d}$ g.a. (Fig. $1 C$ ), when distal air spaces resembled those of the newborn (Fig. 1D). At all ages, the epithelium of airways of all sizes and the medial smooth muscle of accompanying arteries exhibited positive 3,3'-diaminobenzidine tetrahydrochloride reaction product. The distribution of reaction product was greatest at $130 \mathrm{~d}$ g.a., when staining within the parenchyma was more intense than at any other age and could be resolved within the cytoplasm and nucleus of alveolar epithelial and interstitial cells (Fig. $1 E$ ). In the newborn (Fig. 1D) and adult (not shown), parenchymal staining was virtually absent, but immunoreactive MT was still localized in bronchiolar epithelial cells. Preabsorption of diluted antibody with MT-I and MT-II markedly reduced or completely eliminated staining at all ages (Fig. $1 F$ ).

Northern blot analysis for expression of mRNA for four SMT isoforms (and $\beta$-actin) was performed, and results for liver and lung are shown in Figures 2 and 3, respectively. All four isoforms of sMT were readily detectable in hepatic tissue (Fig. 2) of lambs of all ages studied. The sizes of the transcripts were in good agreement with a previous report (19). In contrast to expression in liver, there was no detectable expression of any sMT isoform in either early ( $79 \mathrm{~d}$ g.a.), late (140 d g.a.), or postnatal ( $4 \mathrm{~d}$ and mature) lung (Fig. 3). In saccular lung (120-132 d g.a.), however, there was detectable expression of sMT-II, sMT-Ia, and sMT-Ib but not SMT-Ic. Differences in organ- and age-specific expression of sMT mRNA were not readily accounted for by differences in the amount of RNA because $\beta$-actin mRNA levels were similar between ages within lung (Fig. $3 E$ ) and liver (Fig. $2 E$ ).

The results of normalization of sMT mRNA expression to $\beta$ actin are presented as a composite in Figure $4 A-D$. Although comparisons of relative levels between isoforms is precluded because the analyses were performed under different conditions, salient features within a given isoform between organs and ages 


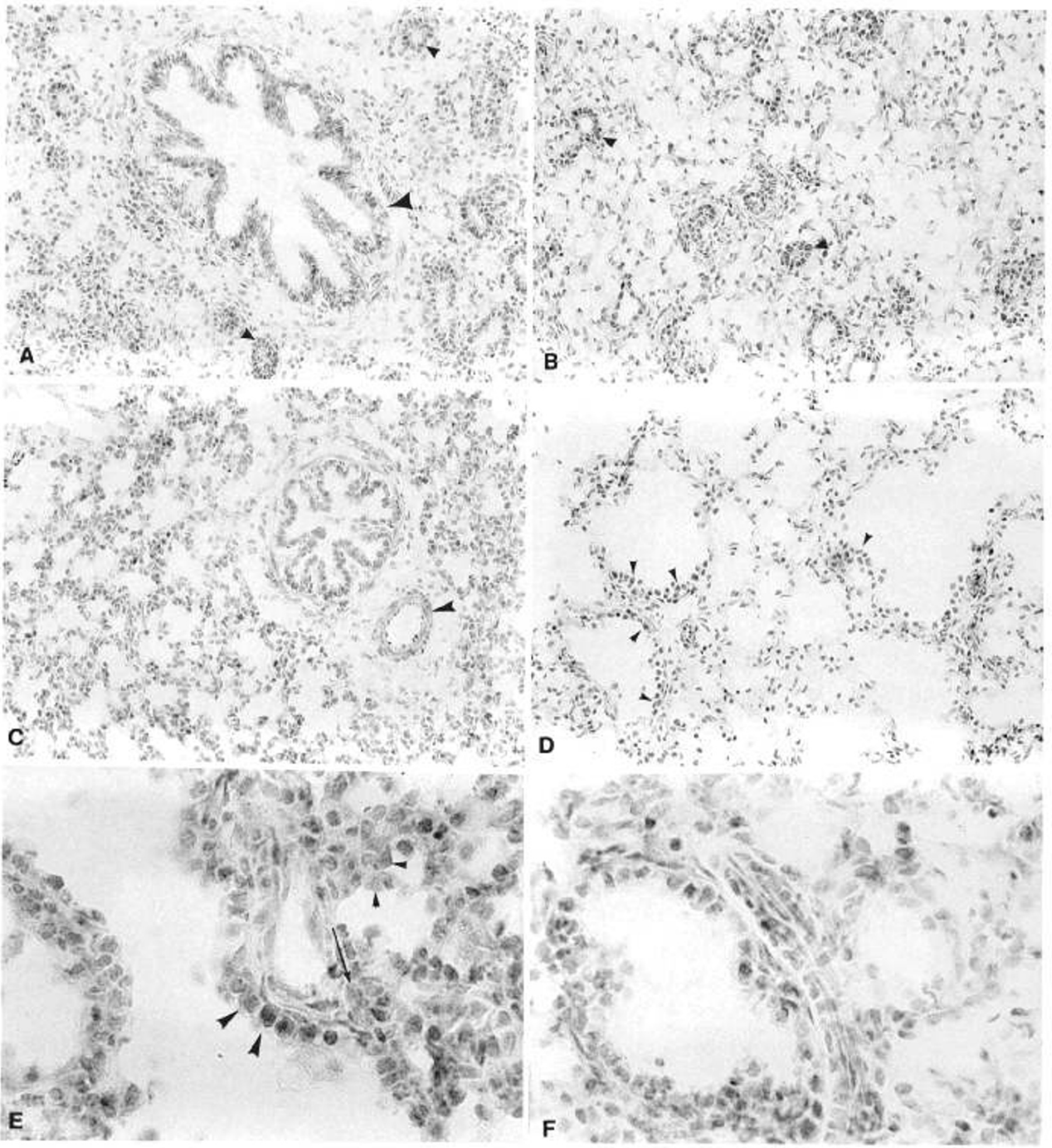

Fig. 1. Immunohistochemical localization of $\mathrm{MT}$ in the developing lamb lung using a rabbit polyclonal antibody and biotin/streptavidinperoxidase signal detection with 3,3'-diaminobenzidine tetrahydrochloride as chromogen. $A, 85 \mathrm{~d}$ g.a. In a bronchiole (large arrowhead) and small putative airways (small arrowheads), epithelial cells are positively stained; most of the mesenchymal stroma is negative. $B, 112 \mathrm{~d}$ g.a. Localization is similar to that in $A$, with staining evident in the epithelium of developing airways (arrowheads). $C, 130 \mathrm{~d}$ g.a. Saccular air spaces are present in the parenchyma, which shows moderate to focally heavy staining; the medial smooth muscle (arrowhead) in the artery accompanying a bronchiole is also positively stained. $D, 4 \mathrm{~d}$ postnatal. Immunolocalization is primarily limited to epithelium of respiratory (arrows) and more proximal (not shown) bronchioles. $E, 130 \mathrm{~d}$ g.a. The high magnification photomicrograph shows positive nuclear and cytoplasmic staining with bronchiolar (large arrowheads) and alveolar (small arrowheads) epithelial cells and interstitial cells (arrows). $F, 130$-d g.a. control, as in $E$, after incubation with excess $\mathrm{MT}$ (see Materials and Methods). Magnification of $A-D, \times 200 ; \mathrm{E}$ and $\mathrm{F}, \times 400$. 
LIVERS

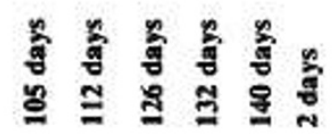

A

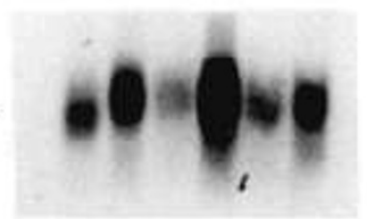

C

sMT-Is

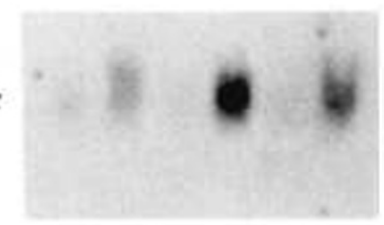

E.

B-Actin

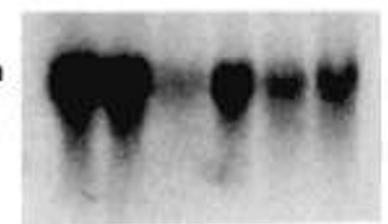

LIVERS

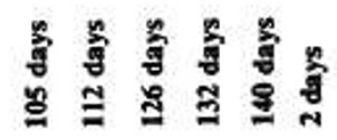

B

sMT-Ib

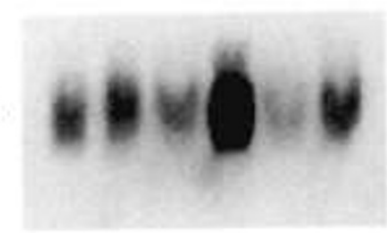

D

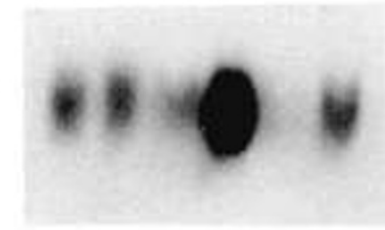

Fig. 2. Northern blot analysis of hepatic expression of sMT isoforms in developing lambs. Each lane contains approximately $10 \mu \mathrm{g}$ of total RNA. Ages from 105 to $140 \mathrm{~d}$ refer to g.a. and postnatal includes liver from 2-d-old lambs. Ribosomal RNA bands visualized by ethidium bromide staining are indicated for reference purposes. Blots were hybridized with ${ }^{32} \mathrm{P}-\mathrm{cDNA}$ probe to sMT-Ia (panel $A$ ), sMT-Ib (panel $\left.B\right)$, sMT-Ic (panel $C$ ), sMTII ( panel $D$ ), and $\beta$-actin (panel $E$ ). Blots were stripped and rehybridized with the above probes in random order on four different occasions from RNA isolated from hepatic tissue.

LUNGS

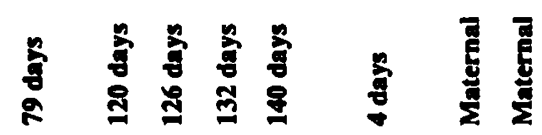

A sMT-la

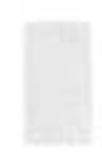

C sMT-Ic

E B-Actin
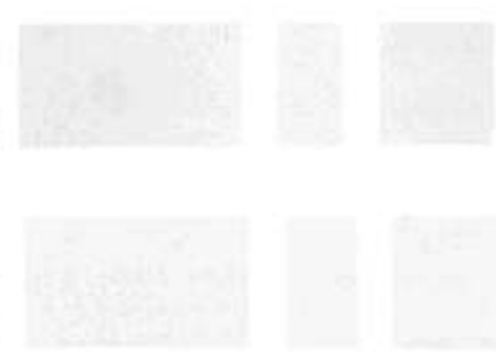

D

sMT-II
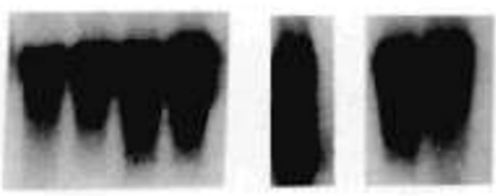

B

sMT.Ib

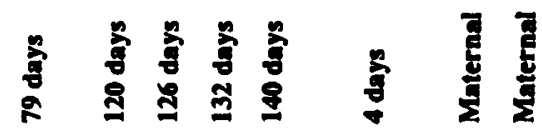

LUNGS (a)

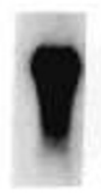

Fig. 3. Northern blot analysis of pulmonary expression of sMT isoforms in developing lambs. Each lane contains approximately $10 \mu \mathrm{g}$ of total RNA. Ages from 79 to $140 \mathrm{~d}$ refer to g.a.; $4 \mathrm{~d}$ is a postnatal lamb, and, in addition, RNA was isolated from two mature (maternal animals). Ribosomal RNA bands visualized by ethidium bromide staining are indicated for reference purposes. Blots were hybridized with ${ }^{32} \mathrm{P}-\mathrm{cDNA}$ probes to SMT-Ia (panel $A$ ), sMT-Ib (panel $B$ ), sMT-Ic (panel $C$ ), sMT-II (panel $D$ ), and $\beta$-actin (panel $E$ ). Blots were stripped and rehybridized with the above probes in random order on four different occasions from RNA isolated from pulmonary tissue. 

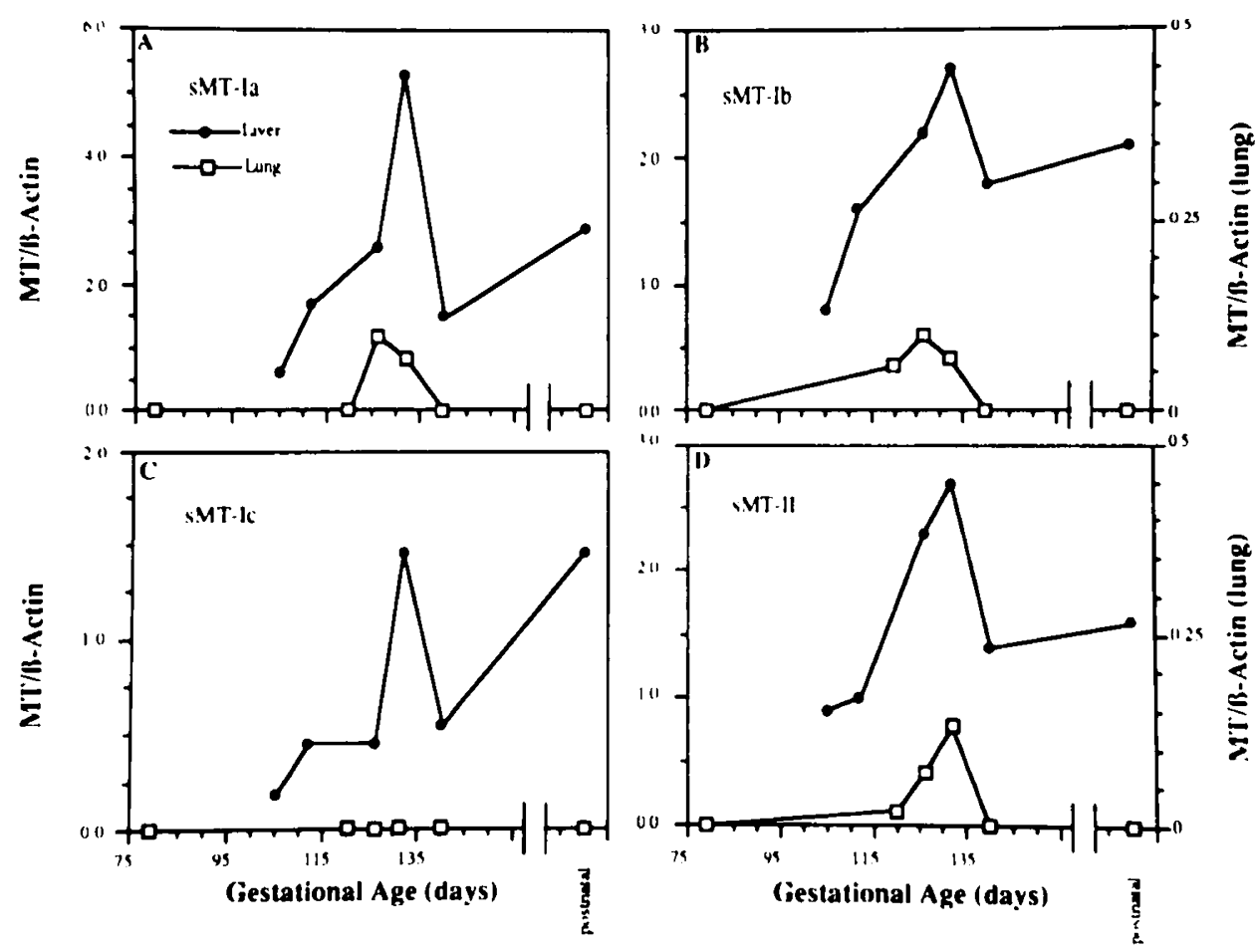

Fig. 4. Relative quantitative expression of mRNA of $M T$ isoforms in developing sheep lung and liver. Northern blots of expression of isoforms of MT were scanned and normalized to mRNA for $\beta$-actin. The relative scale for liver $(\Theta)$ appears on the left hand ordinate and that for lung ( $\square$ ) appears on the right hand ordinate.

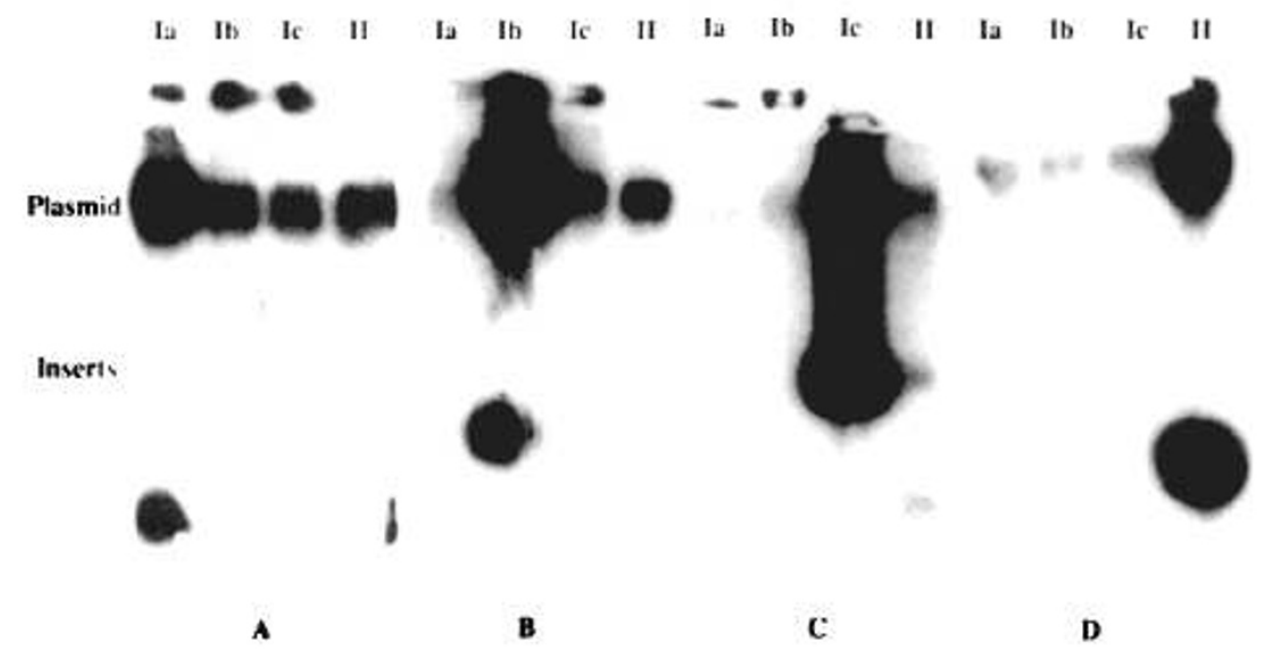

Fig. 5. Autoradiograph of Southern analysis of sMT isoforms. Southern blots of sMT isoforms la. Ib. Ic. and II after digestion with HindIII and ICcoRI were probed with sMT-Ia $(A)$. sMT-Ib $(B)$, sMT-Ic ( $C)$, and SMT-II $(D)$.

include: I) readily measurable levels of hepatic expression of mRNA for all isoforms of MT with lack of detectable levels of sMT-Ic (Fig. $3 C$ ) in lungs of all ages studied; 2) pulmonary expression of detectable levels of sMT-Ia (Fig. 4A), sMT-Ib (Fig. $4 B$ ), and sMT-II (Fig. 4D) mRNA in the saccular period of lung development; and 3) hepatic expression of detectable levels of sMT-Ib and sMT-1I 10-40 times greater than pulmonary expression in the same age animal and sMT-Ia 100-300 times greater in liver than lung. Cross-hybridization of the subisoform cDNA was between 0 and $11 \%$ as determined by Southern blot analysis (Fig. 5).

\section{DISCUSSION}

Requirements for zinc in organogenesis has underscored an interest in MT in developmental biology (24). It is now obvious that zinc has a major structural role in transcriptional proteins in the form of zinc fingers. Recent work (25) suggests that apoMT can affect transcriptional function of zinc finger proteins such as $\mathrm{Spl}$ and TFIIIa. Most studies have focused on a role for MT in hepatic development because liver is the major site of MT synthesis and metal metabolism. If MT has a ubiquitous role in the cell proliferation and differentiation (12), we hypothesized that elevated levels of MT would be apparent during critical periods in extrahepatic organ development. In the present study, we reported detectable expression of MT genes in lung of fetal lambs during the transition between canalicular and saccular development (120-132 d gestation). In addition, we reported for the first time interorgan (lung and liver) age-specific differences in expression of MT isoform mRNA. Because expression of MT isoforms is known to be controlled differently in various mammalian cells (26), potential isoform-specific functions are likely.

Previous immunohistochemical studies failed to identify MT in mature rat lung (16), and in situ hybridization techniques also 
revealed only sparse MT mRNA in newborn rabbit lung (17). Others have shown that, except for a modest elevation immediately at birth, MT protein measured in whole lung homogenates from rat is also very low $(14,15)$. The current study extends these postnatal observations to sheep in that there was no detectable expression of MT mRNA in 4-d-old or mature lung (Fig. 3) and immunolocalization of MT was limited to bronchiolar epithelium of newborn (Fig. 1D) and mature sheep.

Lung development occurs appreciably earlier in sheep than in either rat or rabbit (27). Transition to the saccular stage does not occur until term in rat or rabbit, whereas it is noted at around $120 \mathrm{~d}$ g.a. in sheep. Thus, we hypothesized that expression of MT may be more readily detectable in fetal lamb lung. We detected expression of sMT-II, sMT-Ib mRNA, and sMT-Ia in lungs from fetal lambs (Figs. 3 and 4) of 120-132 d gestation. Concordant with this expression was significant positive immunolocalization of MT to bronchial epithelium and vascular smooth muscle as well as moderate to heavy degrees of staining within the lung parenchyma of 130-d g.a. lamb (Fig. 1C). Parenchymal reactivity could be resolved within alveolar epithelial cells and interstitial cells and was present in both cytoplasmic and nuclear locations (Fig. $1 E$ ). Detection of extensive immunologic reaction product throughout lung parenchyma in the saccular lung is consistent with the detectable level of mRNA expression in this stage of development. Thus, the temporal expression of MT mRNA (Fig. 4) and the cellular (and subcellular) localization of its protein product (Fig. $1 C$ and $E$ ) provide significant correlative documentation that MT participates in remodeling of lung during fetal development. Interestingly, pulmonary MT expression has been induced by exposure of mature and newborn intact animals to high oxygen $(17,28)$ or oxidizing agents such as tert-butylhydroperoxide, paraquat, and 3-methylindole (29), suggesting that MT may also be part of an acute lung injury response. Induction of MT during high oxygen is associated with increased expression in pulmonary fibroblasts, type II cells, and alveolar macrophages $(17,28)$-cells that are critically involved in remodeling. It is less clear why we failed to detect expression of MT mRNA in the 79-d g.a. lung (Fig. 3), whereas there was detectable immunoreactive product in the 85d g.a. lung (Fig. 1 $A$ ). It is likely that the compartmentalization of MT antigen to bronchiolar epithelium precluded detection of mRNA from whole lung parenchyma at this stage of development. It is also possible that translational efficiency was greater in the earlier aged fetal lung, providing greater protein per mRNA; such a change in translational efficiency has been reported in developing sheep liver (11).

The mechanisms underlying regulation of MT expression in lung remain unclear. A recent report regarding regulation of MT expression in fetal sheep liver (11) has discounted a role for glucocorticoids. Paynter et al. (11) hypothesized that intrahepatic zinc levels may regulate ovine MT expression in a physiologic attempt to maintain free zinc levels below potential toxic levels. Because copper levels are quite low in lung (and liver) of developing sheep (30), this particular metal is not a likely candidate for intrapulmonary MT regulation. Because relative hypomethylation of DNA may also up-regulate MT expression, it is possible that such changes may have occurred during lung development. It also remains to be determined why there is an apparent isoform-specific expression within developing lung. In this regard, although we cannot directly compare isoform expressions quantitatively, we are left with the impression that hepatic sMTIb was detectable within the limits of expression of hepatic sMTII and sMT-Ia (Figs. 2 and 4) or SMT-II in lung (Figs. 3 and 4). This is in contrast to the low abundance of sMT-Ib in mature sheep liver noted by Peterson and Mercer (19) and presumably represents an intrastrain or environmental difference between sheep reared in Australia and those reared in the United States.

In summary, detectable levels of expression of MT mRNA and protein were noted during the saccular stage of lung development in sheep. In addition, MT isoform specificity was noted at the mRNA level, inasmuch as only three of four isoforms measured were detectable by Northern blotting. Expression of fetal pulmonary MT mRNA was one to two orders of magnitude less than expression of MT mRNA in liver, the presumptive major site of MT biosynthesis. Nonetheless, its discrete pattern of expression and its localization to epithelial and interstitial cells (including nuclear staining) of the parenchyma of the saccular lung suggest a role for MT during significant alveolar remodeling.

Acknowledgments. The authors thank Karla Wasserloos, Joseph DeFillippo, and Lynn Patsiga for their technical assistance. We thank Dr. Julian F. B. Mercer (Victoria, Australia) for the gift of sMT cDNA probes.

\section{REFERENCES}

1. Hamer DH 1986 Metallothionein. Annu Rev Biochem 55:913-951

2. Karin M 1985 Metallothioneins: proteins in search of function. Cell 41:9-10

3. Karin M, Richards RI 1984 The human metallothionein gene family: structure and expression. Environ Health Perspect 54:111-115

4. Peterson MG, Hannan F, Mercer JFB 1988 The sheep metallothionein gene family. Structure, sequence and evolutionary relationship of five linked genes. Eur J Biochem 174:417-424

5. Kagi JHR, Schaffer A 1988 Biochemistry of metallothionein gene family. Structure, sequence and evolutionary relationship of five linked genes. Eur J Biochem 174:417-424

5. Kagi JHR, Schaffer A 1988 Biochemistry of metallothionein. Biochemistry 27:8509-8515

6. Webb M, Cain IK 1982 Functions of metallothionein. Biochem Pharmacol 31:137-142

7. Anderson RD, Piletz JE, Birren BW, Herschman HR 1983 Levels of metallothionein messenger RNA in fetal, neonatal and maternal rat liver. Eur J Biochem 131:497-500

8. Andrews GK, Adamson EK, Gedamu L 1984 The ontogeny of expression of murine metallothionein: comparison with the alpha-fetoprotein gene. Dev Biol 103:294-303

9. Mercer JFB, Grimes A 1986 Variation in the amounts of hepatic copper, zinc and metallothionein mRNA during development in the rat. Biochem J 238:23-27

10. Lehman-Mckeeman LD, Andrews GK, Klassen CD 1988 Ontogeny and induction of hepatic isometallothioneins in immature rats. Toxicol Appl Pharmacol 92:10-17

11. Paynter JA, Camakaris J, Mercer JFB 1990 Analysis of hepatic copper, zinc, metallothionein and metallothionein-Ia mRNA in developing sheep. Eur $J$ Biochem 190:149-155

12. Kern SR, Smith HA, Fontaine D, Bryan SE 1981 Partitioning of zinc and copper in fetal liver subfractions: appearance of metallothionein-like proteins during development. Toxicol Appl Pharmacol 59:346-354

13. Quaife C, Hammer RE, Mottet NK, Palmiter RD 1986 Glucocorticoid regulation of metallothionein during murine development. Dev Biol 118:549555

14. Waalkes MP. Klaassen CD 1984 Postnatal ontogeny of metallothionein in various organs of the rat. Toxicol Appl Pharmacol 74:314-320

15. Hart BA, Voss GH, Garvery JS 1991 Metallothionein in rat lung during postnatal development. Biol Neonate 59:236-243

16. Hart BA, Cherian MG, Angel A 1985 Cellular localization of metallothionein in the lung following repeated cadmium inhalation. Toxicology 37:171-179

17. Veness-Mehan KA, Cheng ERY, Mercier CE, Blixit SL, Johnston CJ, Watkins RH, Horowitz S 1991 Cell-specific alterations in expression of hyperoxiainduced mRNA's of lung. Am J Respir Cell Mol Biol 5:516-521

18. Kelley SL, Basu A, Teischer BA, Hacker MP, Hammer DH, Lazo JS 1988 Overexpression of metallothionein confers resistance to anticancer drugs. Science 241:1813-1815

19. Peterson MG, Mercer JFB 1988 Differential expression of four linked sheep metallothionein genes. Eur J Biochem 174:425-429

20. Chomczynski P, Sacchi N 1987 Single-step method of RNA isolation by acid guanidium thiocyanate-phenol-chloroform extraction. Anal Biochem 162:156-159

21. Church GM, Gilbert W 1984 Genomic sequencing. Proc Natl Acad Sci USA 81:1991-1995

22. Gunning P, Ponte P, Odayam H, Engel J, Blau H, Kedes L 1983 Isolation and characterization of full-length cDNA clones for human $\alpha-\beta$ - and $\gamma$-actin mRNAs: skeletal but not cytoplasmic actins have an amino-terminal cysteine that is subsequently removed. Mol Cell Biol 3:787-795

23. Fleet JC, McCormick CC 1988 The ontogeny and induction by zinc of hepatic chick embryo metallothionein. Proc Soc Exp Biol Med 188:52-60 
24. Bremner I, Beattie JH 1990 Metallothionein and the trace minerals. Annu Rev Nutr 10:63-83

25. Zeng J, Vallee BL, Kagi JHR 1991 Zinc transfer from transcription factor IIIA fingers to thionein clusters. Proc Natl Acad Sci USA 88:9984-9988

26. Jahroudi N, Foster R, Price-Haughey J, Beitel G, Gedamu L 1990 Cell-type specific and differential regulation of human metallothionein genes. $J$ Biol Chem 265:6506-6511

27. Meyrick B, Reid LM 1977 Ultrastructure of alveolar lining and its development. In: Hodson WA (ed) Development of the Lung. Marcel Dekker, New
York, pp 135-214

28. Hart BA, Voss GW, Shatos MA, Doherty J 1989 Induction of pulmonary metallothionein following oxygen exposure. Environ Res 50:269-278

29. Bauman JW, Liu J, Liu YP, Klaassen CD 1991 Increase in metallothionein produced by chemicals that induce oxidative stress. Toxicol Appl Pharmacol 110:347-354

30. Pryor WJ 1964 The distribution of copper in bovine and ovine foetuses, with reference to their age and maternal liver copper concentrations. Res Vet Sci 5:123-137

\section{Announcement}

\section{Manuscripts on Electronic Diskettes \\ Preparation of Disks}

Authors are encouraged to submit electronic diskettes of the final version of their manuscripts along with the typed REVISED manuscript. Diskettes produced on IBM or IBM-compatible computers are preferred, but those produced on most Apple/Macintosh or Wang computers can also be converted. The following word processing programs are preferred: XyWrite III Plus, Word Perfect 4.2, 5.0, or 5.1 (IBM or Macintosh), Microsoft Word (IBM or Macintosh), Wang OIS (WPS), and Wordstar (IBM). Among other word processing systems that we can convert are CPT 8000 , MacWrite 2.2 or 4.5 , Display Write 3 or 4 , Multimate, PC Write, Volkswriter, and Write Now. Authors preparing diskettes on Macintosh computers should not use the Fast Save option. Files in ASCII can also be used, but are not preferred. Identify the diskette by providing journal name, manuscript number, senior author's name, manuscript title, name of computer file, type of hardware, operating system and version number, and software program and version number.

The Journal does not assume responsibility for errors in conversion of customized software, newly released software, and special characters. Mathematics and tabular material will be processed in the traditional manner. 